Research Article

\title{
Profile of Animal Bite Cases in a Tertiary Care Hospital in Mysuru
}

\author{
Harshini Suresh', Mansoor Ahmed ${ }^{2}$, Mudassir Azeez Khan ${ }^{3}$
}

${ }^{1}$ Postgraduate, ${ }^{2}$ Associate Professor, ${ }^{3}$ Professor, Department of Community Medicine, Mysore Medical College \& Research Institute, Mysuru, Karnataka, India.

DOI: https://doi.org/10.24321/2454.325X.202104

\section{I $\quad \mathbf{N} \quad \mathbf{F} \quad \mathbf{O}$}

\author{
Corresponding Author: \\ Mansoor Ahmed, Department of Community \\ Medicine, Mysore Medical College \& Research \\ Institute, Mysuru, Karnataka, India. \\ E-mail Id: \\ docmansoor2000@yahoo.com \\ Orcid Id: \\ https://orcid.org/0000-0001-5929-067X \\ How to cite this article: \\ Suresh $\mathrm{H}$, Ahmed M, Khan MA. Profile of Animal \\ Bite Cases in a Tertiary Care Hospital in Mysuru. \\ Int J Preven Curat Comm Med. 2021;7(1):25-29. \\ Date of Submission: 2021-03-01 \\ Date of Acceptance: 2021-03-28
}

\section{$\begin{array}{llllllll}\mathbf{A} & \mathbf{B} & \mathbf{S} & \mathbf{T} & \mathbf{R} & \mathbf{A} & \mathbf{C} & \mathbf{T}\end{array}$}

\begin{abstract}
Animal bites cause a big burden worldwide in terms of morbidity and mortality. As per WHO, dog bites are the cause of major animal bite injuries followed by snake bites, cat bites, and monkey bites. Annually about 55,000-60,000 persons die of rabies, of which nearly one-third are from India alone. Rabies, though being a $100 \%$ fatal disease, is also a potentially preventable disease.
\end{abstract}

Objective: To estimate the proportion of animal bites in patients attending anti-rabies clinic of a tertiary hospital, Mysuru.

Material \& Methods: A cross-sectional study was carried out during the period of June 2018 - May 2019. Secondary data was collected from the registers available at the anti-rabies clinic in KR Hospital, Mysuru, using a pretested proforma. This information was compiled in an excel sheet and analysed using simple measures like proportions, percentages, and graphs.

Results: A total of 3861 animal bite cases were reported, out of which, $69.1 \%$ were males and $30.9 \%$ were females. Dog bites contributed the highest (92.1\%) followed by cat bites (5.2\%). As per the category of wounds, 59.6\% were Category 2 and $36.2 \%$ were Category 3 wounds.

Conclusion: Dog bite is the commonest animal bite which needs to be addressed as a priority with appropriate preventive strategies. There is a pressing need to create awareness among the general population about the need for timely health care seeking behaviour and to avail the benefit of free anti-rabies vaccination in the public health sector in order to prevent the risk of fatal events.

Keywords: Rabies, Animal Bite, Anti-rabies Clinic, Category of Bite

\section{Introduction}

Rabies is a zoonotic disease caused by the rabies virus and most commonly transmitted by animal bites. It is one of the ten leading causes of death due to infectious diseases across the world. ${ }^{1}$ The disease occurs in over 150 countries throughout the world and poses a great threat to more than 3 billion people worldwide. Around 60,000 human deaths are still reported across the world, with nearly $80 \%$ of them reported from Asian countries. ${ }^{2}$ India reports about 18,000-20,000 cases of rabies per year. ${ }^{3}$ In India, animal bite has been a major public health problem and an estimated 17.4 million animal bites occur annually, which amounts to 
an incidence of $1.7 \%$. There is one rabies death every 30 minutes and one animal bite every 2 seconds in the country. ${ }^{4}$ Although a number of carnivores and bat species serve as natural reservoirs of the rabies virus, domestic dogs are the most common reservoir, and more than $95 \%$ of human deaths are caused by dog-mediated rabies. ${ }^{2}$

Although $100 \%$ fatal, rabies can be prevented by timely interventions like wound washing, avoiding unnecessary suturing, and by the administration of Anti-Rabies Vaccine (ARV) and rabies immunoglobulin. Globally, about 15 million people take rabies Post-Exposure Prophylaxis (PEP) every year. The high mortality from rabies can be ascribed to the fact that in spite of the availability of effective PEP, people are mostly unaware of the seriousness of the disease and its prevention. ${ }^{5}$

The Indian Government has adopted guidelines for rabies vaccination from the World Health Organization (WHO). Anti-rabies vaccination requires only a small quantity of vaccine to be injected into the skin. It is $60-80 \%$ cheaper than the usual vaccination by the intramuscular route. Also, by this intradermal route, the compliance will be high due to less number of visits and decreased cost of regimen. ${ }^{3}$

In India, rural people are the major victims of rabies. The main reason for the risk of rabies among rural populations is their ignorance about the grave nature of the disease, common myths and misconceptions related to the treatment of animal bite wounds, inaccessibility to healthcare centres, and non-availability of rabies biologicals at an affordable cost. 6,7

\section{Material \& Methods}

The present cross-sectional study was conducted in the Anti-Rabies Clinic (ARC) of Krishna Rajendra Hospital which is a tertiary hospital of Mysuru after obtaining ethical clearance from the Institutional Ethics Committee of Mysore Medical College \& Research Institute, Mysuru. The method of data collection employed was by making use of secondary data from the various registers available in the anti-rabies clinic. The basic information available in the registers were collected. The study period was from June 2018 to May 2019. The total number of cases registered during this period was 3861 . All patients registered in the anti-rabies clinic were included in the study. The socio-demographic data of the cases were noted down and the factors related to the dog bite such as type of animal bite, category of bite, site of bite, time since bite, and compliance of patients with reference to the doses of vaccine were collected from the anti-rabies register and compiled.

\section{Statistical Analysis}

Data were entered and analysed in a Microsoft Excel sheet and descriptive statistics such as percentages and proportions were calculated with reference to the proportion of animal bites and the associated factors. Graphical methods of data representation such as bar charts and pie charts were used for depicting the category of bite, site of bite, and time since bite.

\section{Results}

Among 3861 animal bite cases (Table 1), maximum were reported among males (69.1\%) and in people aged between 20-50 years (48.1\%). In this study, the major animal bite was found to be dog bite (92\%) followed by cat bite (5\%).

Table I.Socio-demographic Profile of the Patients

\begin{tabular}{|c|c|c|}
\hline Characteristics & Frequency (n) & Percentage (\%) \\
\hline \multicolumn{3}{|c|}{ Gender } \\
\hline Male & 2671 & 69.1 \\
\hline Female & 1190 & 30.9 \\
\hline \multicolumn{3}{|c|}{ Age (years) } \\
\hline 20 & 1249 & 32.3 \\
\hline $20-50$ & 1853 & 48.1 \\
\hline$>50$ & 759 & 19.5 \\
\hline Dog & 3552 & 92 \\
\hline Cat & 193 & 5 \\
\hline Others & 116 & 3 \\
\hline
\end{tabular}

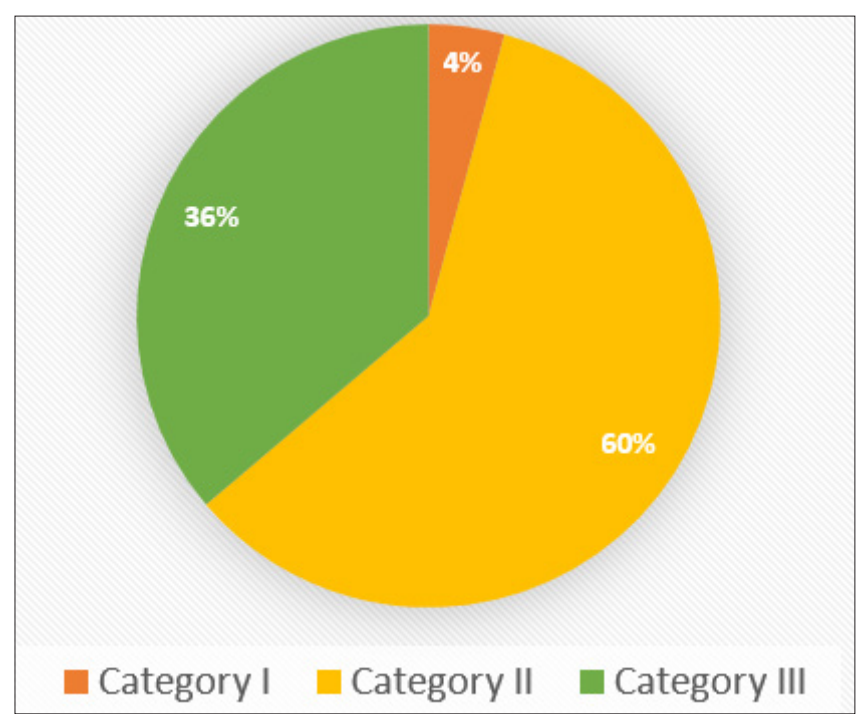

\section{Figure I.Distribution of Subjects according to Category of Bite}

Figure 1, shows that majority of the bites were of category II (60\%), followed by category III (36\%).

According to Figure 2, the most common site of bite was lower $\operatorname{limb}(61 \%, n=2352)$ followed by upper limb $(29.5 \%$, $\mathrm{n}=1140)$.

Figure 3 , shows the time taken by the patients to avail 
treatment after the animal bite. Majority of the people $(61.3 \%, n=2367)$ reported to the anti-rabies clinic between 6 to 24 hours after the bite.

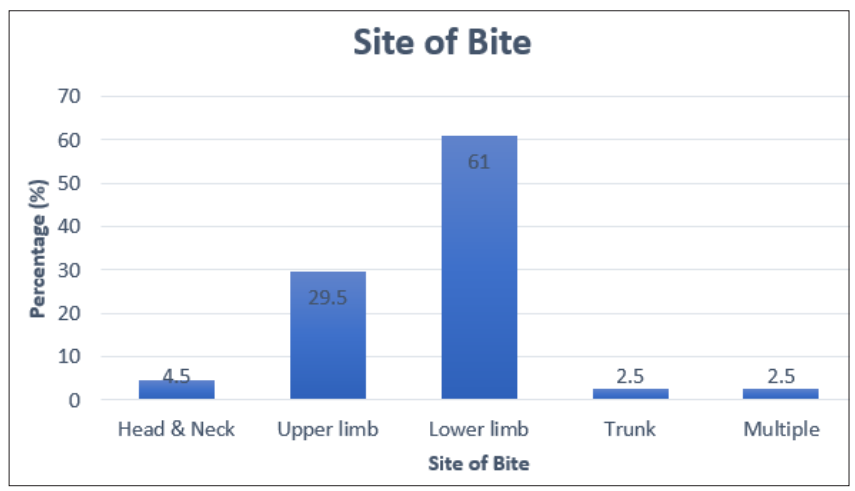

Figure 2.Distribution of Subjects according to Site of Bite

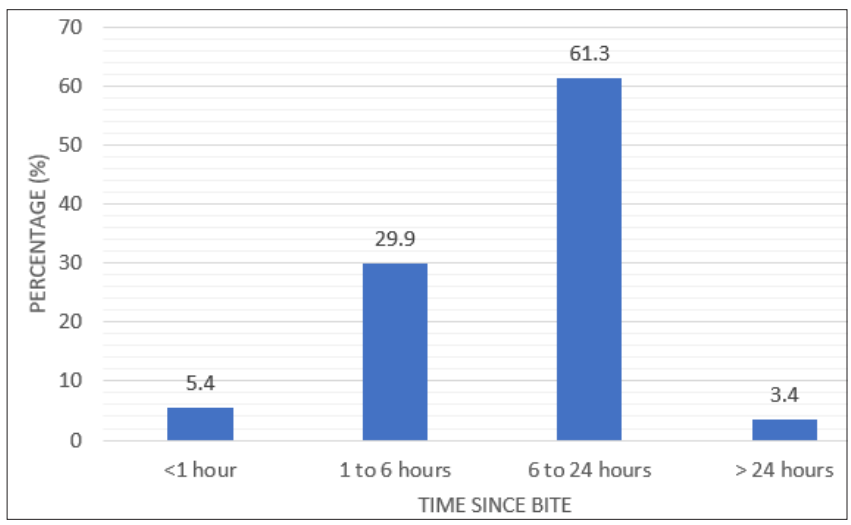

Figure 3.Time taken for Treatment after Animal Bite

Table 2.Monthly Distribution of Vaccinated Animal bite cases

\begin{tabular}{|c|c|}
\hline Month & Total Number of Cases \\
\hline June 2018 & 323 \\
\hline July 2018 & 336 \\
\hline August 2018 & 345 \\
\hline September 2018 & 357 \\
\hline October 2018 & 292 \\
\hline November 2018 & 340 \\
\hline December 2018 & 317 \\
\hline January 2019 & 310 \\
\hline February 2019 & 185 \\
\hline March 2019 & 349 \\
\hline April 2019 & 379 \\
\hline May 2019 & 328 \\
\hline
\end{tabular}

Table 2, shows the monthly distribution of animal bite cases. The distribution of cases were almost the same in all months. Due to non-availability of vaccine during the month of February 2019, only 185 patients got vaccinated.

A total of 3861 animal bite cases were treated at the anti-rabies clinic during the study period. The 1st dose of intradermal rabies vaccine was given to the patients on the 1st day of visit to the ARV clinic $(n=3861)$. The patients were advised to return on day 3,7 , and 28 to complete the full schedule, but it was observed that only 2841 (73.6\%) patients returned for the 2nd dose. Further, the compliance dropped for the $3 r d$ and 4 th doses $(48.7 \%$ and $23.5 \%$ respectively) (Table 3 ). It was observed that only $23.5 \%$ of the registered cases completed the full schedule of immunisation in this clinic.

Table 3.Compliance Rate of ARV Doses

\begin{tabular}{|c|c|c|}
\hline Doses & Number of Vaccines & Compliance Rate (\%) \\
\hline 1st & 3861 & 100 \\
\hline 2nd & 2841 & 73.6 \\
\hline 3rd & 1884 & 48.7 \\
\hline 4th & 908 & 23.5 \\
\hline
\end{tabular}

\section{Discussion}

Animal bite is a major public health problem in India. In this study, a total of 3861 cases of animal bites were reported in the anti-rabies clinic of KR hospital during the study period.

It was observed that males (69.1\%) were more affected than females (30.9\%). This was in consonance with other studies done by Sangeetha et al., ${ }^{8}$ Bharadva et al., ${ }^{9}$ Vinay et al., ${ }^{10}$ and Nikhil et al., ${ }^{11}$ The possible reason behind this may be that more males go out for work as compared to females.

A majority of cases with animal bites in this study were aged between $20-50$ years (48.1\%). Studies done by Sangeetha et al.8, Bharadva et al., ${ }^{9}$ Vinay et al. ${ }^{10}$ and Amrutha et al.. ${ }^{4}$ showed results similar to that of this study, but in the study done by Nikhil et al., ${ }^{11}$ the affected age group was 11-20 years. This may be due to the fact that young individuals might be involved in more outdoor activities.

The dominant category of bite in this study was observed to be category II (60\%). This was in consonance with the studies done by Sangeetha et al. ${ }^{8}$ and Amrutha et al., ${ }^{4}$ whereas, in a few other studies done by Venu Shah et al., ${ }^{12}$ Samreen et al. ${ }^{13}$ and Kumar et al., ${ }^{14}$ the victims mostly had category III animal bite.

Majority of the people in this study had animal bites in their lower limbs (60.9\%). This was similar to the findings in studies done by Bharadva et al., ${ }^{9}$ Venu Shah et al., ${ }^{12}$ Meena et al. ${ }^{15}$ 
In this study, the time taken by majority of the patients to avail treatment after the animal bite was between 6 to 24 hours (61.3\%). In this regard, there were many variations in the findings reported by other studies. Sangeetha et al., 8 observed that most of the patients reported in less than half an hour. In a study by Bharadva et al., ${ }^{9}$ many patients reported between 1 to 6 hours after the animal bite. In other studies by Venu Shah et al., ${ }^{12}$ Meena et al., ${ }^{15}$ most of the patients reported after 24 hours of animal bite. This variation among these studies depends upon people's awareness of the problem of animal bites. In this regard, awareness regarding animal bites and early initiation of treatment should be improved among the people.

In the current study, the compliance rate of completing all 4 doses of vaccine was $23.5 \%$ which is very low as compared to a study done by Amrutha et al., ${ }^{4}$ where the compliance rate of completing all 4 doses was $40.8 \%$. This may be due to the fact, that other people would have taken their doses in the nearby hospitals or Primary health centres and some people would have missed their doses.

\section{Conclusion}

This study indicates that animal bites constititute a significant yet neglected public health problem in our country which needs to be addressed as a priority with appropriate preventive and control strategies. There is a pressing need to create awareness among the general population about the need for timely health care seeking behaviour and to avail the benefit of free anti-rabies vaccination in the public health sector in order to prevent the risk of fatal events. The need for rabies immunoglobulin in severe category of bites also has to be emphasised. Peer-based behaviour change communication and advocacy will play a great role to achieve this goal. Also, there is a need to broadcast educational programmes through mass media for creating awareness among the people regarding the complication and prevention of animal bites and to avoid contact with stray dogs. On the other hand, the health officials should take measures to control stray dogs and intensify pet dog vaccination as much as possible. Similar studies in other regions also are highly recommended.

Table 4.Summary of Articles in Discussion

\begin{tabular}{|c|c|c|c|c|c|c|c|}
\hline Author's Name/ Study Year & $\begin{array}{c}\text { Geographic } \\
\text { Location }\end{array}$ & $\begin{array}{c}\text { Most } \\
\text { Commonly } \\
\text { Affected } \\
\text { Gender }\end{array}$ & $\begin{array}{c}\text { Affected } \\
\text { Age } \\
\text { Group } \\
\text { (years) }\end{array}$ & $\begin{array}{c}\text { Category } \\
\text { of Bite }\end{array}$ & $\begin{array}{c}\text { Type of } \\
\text { Animal } \\
\text { Bite }\end{array}$ & $\begin{array}{c}\text { Most } \\
\text { Common } \\
\text { Site of } \\
\text { Bite }\end{array}$ & $\begin{array}{c}\text { Time } \\
\text { Taken to } \\
\text { Reach } \\
\text { Hospital }\end{array}$ \\
\hline $\begin{array}{c}\text { Venu Shah et al./ } \\
2012^{12}\end{array}$ & Gujarat & Male & $15-24$ & III & Dog & $\begin{array}{c}\text { Lower } \\
\text { limb }\end{array}$ & $\begin{array}{c}>24 \\
\text { hours }\end{array}$ \\
\hline $\begin{array}{c}\text { Vinay et al./ } \\
2013^{10}\end{array}$ & Pondicherry & Male & $11-20$ & - & Dog & - & - \\
\hline $\begin{array}{c}\text { Nikhil et al./ } \\
2014^{11}\end{array}$ & Karnataka & Male & $15-60$ & - & Dog & $\begin{array}{c}\text { Upper } \\
\text { limb }\end{array}$ & - \\
\hline $\begin{array}{c}\text { Jahnavi et al./ } \\
2015^{9}\end{array}$ & Gujarat & Male & $15-45$ & III & Dog & $\begin{array}{c}\text { Lower } \\
\text { limb }\end{array}$ & $1-6$ hours \\
\hline $\begin{array}{c}\text { Bharadva et al./ } \\
2015^{9}\end{array}$ & Tamil Nadu & Male & $26-45$ & II & Dog & $\begin{array}{c}\text { Lower } \\
\text { limb }\end{array}$ & $\begin{array}{c}<1 / 2 \text { an } \\
\text { hour }\end{array}$ \\
\hline $\begin{array}{c}\text { Sangeetha et al./ } \\
2016^{8}\end{array}$ & Karnataka & Male & $15-45$ & II & Dog & - & - \\
\hline $\begin{array}{c}\text { Amrutha et al./ } \\
2017^{4}\end{array}$ & Kashmir & Male & $21-30$ & III & Dog & $\begin{array}{c}\text { Lower } \\
\text { limb }\end{array}$ & - \\
\hline $\begin{array}{c}\text { Samreen et al./ } \\
2019^{13}\end{array}$ & Rajasthan & Male & $26-45$ & - & Dog & $\begin{array}{c}\text { Lower } \\
\text { limb }\end{array}$ & $\begin{array}{c}>24 \\
\text { hours }\end{array}$ \\
\hline $\begin{array}{c}\text { Meena et al./ } \\
2019^{15}\end{array}$ & Himachal \\
\hline $\begin{array}{c}\text { Kumar et al./ } \\
2019^{14}\end{array}$ & Male & $21-30$ & III & Dog & $\begin{array}{c}\text { Lower } \\
\text { limb }\end{array}$ & - \\
\hline \begin{tabular}{c} 
Pradesh \\
\hline
\end{tabular}
\end{tabular}




\section{Conflict of Interest: None}

\section{Source of Funding: None}

\section{References}

1. Baxter JM. One in a million, or one in thousand: What is the morbidity of rabies in India? J Global Health. 2012;2(1):010303. [PubMed] [Google Scholar]

2. WHO [Internet]. Rabies; [cited 2020 Oct 26]. Available from: https://www.who.int/news-room/fact-sheets/ detail/rabies

3. Yashodha V, Paul B. Epidemiology and immunoprophylaxis compliance of animal bite cases at an immunization clinic of a tertiary care hospital, in Haryana. Assoc Prev Control Rabies India. 2015;17:23.

4. Amrutha AM, Naveen KH, Sushma J. Profile of Animal Bite Cases Attending Anti-rabies Clinic of a Government Tertiary Care Hospital in Mysore and their Compliance to 4-Dose Intradermal Rabies Vaccine. Ann Community Health. 2018 Jan 1;5(4):2-5.

5. Mohanty M, Satapathy DM, Mishra A. Incomplete and improper post exposure treatment leading to rabies: $A$ case study. Assoc Prev Control Rabies India. 2015;17:26. [Google Scholar]

6. Sudarshan MK, Nagaraj S, Savitha B, Veena SG. An epidemiological study of rabies in Bangalore city. J Indian Med Assoc. 1995;93:14-6. [PubMed] [Google Scholar]

7. Gohil HK, Dhillon R, Tiwari KN. Human rabies situation in and around Delhi. J Assoc Prev Control Rabies India. 2003;5(2):11-5.

8. Sangeetha S, Sujatha K, William RF. An epidemiological study of animal bites among rural population in Tamil Nadu, India. Int J Community Med Public Health. 2017 Jan 5;3(6):1413-8.

9. Bharadva N, Mehta SR, Yerpude P, Jogdand K, Trivedi KN. Epidemiology of Animal Bite Cases Attending Tertiary Health Care Centre of Bhuj City of India: A Cross-Sectional Study. Int J Interdiscip Multidiscip Stud. 2015 Jul 1;2:98-102. [Google Scholar]

10. Vinay M, Mahendra BJ, Nagaraj GB, Bullappa A, Ananthachari KR, Sheethal MP. Socio-demographic characteristics affecting compliance to intra dermal rabies vaccination at anti rabies clinic in a government tertiary care hospital in Karnataka. J Evol Med Dent Sci. 2013 Sep 16;2(37):7090. [Google Scholar]

11. Nikhil SV, Rizwan SA, Chellaiyan VG, Kavita V, Upadhyay RP, Palanivel C. Profile of Patients Attending an Animal Bite Management Clinic in Rural Pondicherry, India. Int J Trop Dis Health. 2014 Jan 14;4:306-10. [Google Scholar]

12. Shah V, Bala DV, Thakker J, Dalal A, Shah U, Chauhan S, Govani K. Epidemiological determinants of animal bite cases attending the anti- rabies clinic at V S General Hospital, Ahmedabad. Healthline. 2012;3(1):66-8.
[Google Scholar]

13. Samreen S, Ashraf A, Hassan M, Khan SM. Profile of Animal Bite Cases at Anti-Rabies Clinic of Tertiary Care Hospital: A Record Based Study. J Med Sci Clin Res. 2019;7(4):893-6. [Google Scholar]

14. Kumar S, Gupta A, Sachdeva A, Chaudhary A, Chamotra S. Epidemiological profile of animal bite patients attending emergency department at a tertiary care health facility in a northern hilly Indian city. Int J Community Med Public Health. 2019 Jun 28;6(7):30147. [Google Scholar]

15. Sharma N, Meena G, Rathore M, Verma M, Raj D, Yadav R. To study epidemiological profile of dog bite cases attending anti rabies centre at SMS Hospital, Jaipur and pretreatment practices adopted by them following animal bite. J Med Sci Clin Res. 2019;7(8):117-20. [Google Scholar]

16. Janhavi R, Vinay M, Manuja LM, Anil KK. Clinico epidemiological profile of wild animal bite victims attending anti rabies clinic at government tertiary care centre in Mandya. J Evol Med Dent Sci. 2014 Nov 28;3(66):14257-61. [Google Scholar] 